INTERNATIONAL JOURNAL OF MULTidisciplinARY RESEARCH AND ANALYSis

ISSN(print): 2643-9840, ISSN(online): 2643-9875

Volume 05 Issue 02 February 2022

DOI: 10.47191/ijmra/v5-i2-43, Impact Factor: 6.072

Page No. 549-555

\title{
ABM Method: The Application of Traditional Festival Elements in Interactive Packaging Design
}

\author{
Qinmi $\mathbf{Y u}^{1}$, Jirawat Vongphantuset ${ }^{2}$ \\ ${ }^{1}$ College of arts and design, Guilin University of Technology, Guilin, China \\ Decorative Arts Faculty, Silpakorn University, Bangkok, Thailand \\ ${ }^{2}$ Decorative Arts Faculty, Silpakorn University, Bangkok, Thailand
}

\begin{abstract}
This article mainly focuses on the application of Yao Panwang Festival elements on interactive packaging design for local products, discusses the interactive packaging as a carrier to convey the festival cultural spirit. The methods ABM: Analysis(festival contents)-Build relationship (traditional vs modern)-Media(interactive package,toy,emoji,etc.). This article builds the "Interactive Packaging Design Analysis Table" to explore and evaluate. The interactive packaging features are expressed through three parts: packaging structure, Packaging visual information and function extension. This research helps to improve the cultural and tourism experience, promote economic development and reduce environmental pressure.
\end{abstract}

KEYWORDS: ABM method, festival, interactive packaging design

\section{INTRODUCTION}

Traditional festivals are one of the representative symbols of regional culture, it has high cultural value under the context of post-modern consumption. Festivals are a concentrated reflection of the local life-style, it provide a content basis for cultural tourism experience(Liu B,2017), it also as an important part of cultural exchanges and cultural experience. Under the worldwide online shopping style and the logistics system, the local specialty packages can be as solid advertising carrier that shapes the image of local culture and an important carrier for constructing cultural identity.

Follow the green design concept, the life of interactive packaging is prolonged than disposable packaging box, and the packaging undergoes functional transformation during use or after the protect function is completed; the dynamic information transmission characteristics more effective and interesting when customers "play" with the packages, At the same time, customers receive information more proactively. It can be seen that interactive packaging has certain advantages over traditional disposable packaging.

Based on the above two points, this study takes the application of Panwang Festival elements in packaging interactive design as an example, The motivate is combines festival and interactive packaging design, and to provide reference to drive rural sustainable development. The following is the research framework(fig.1). 


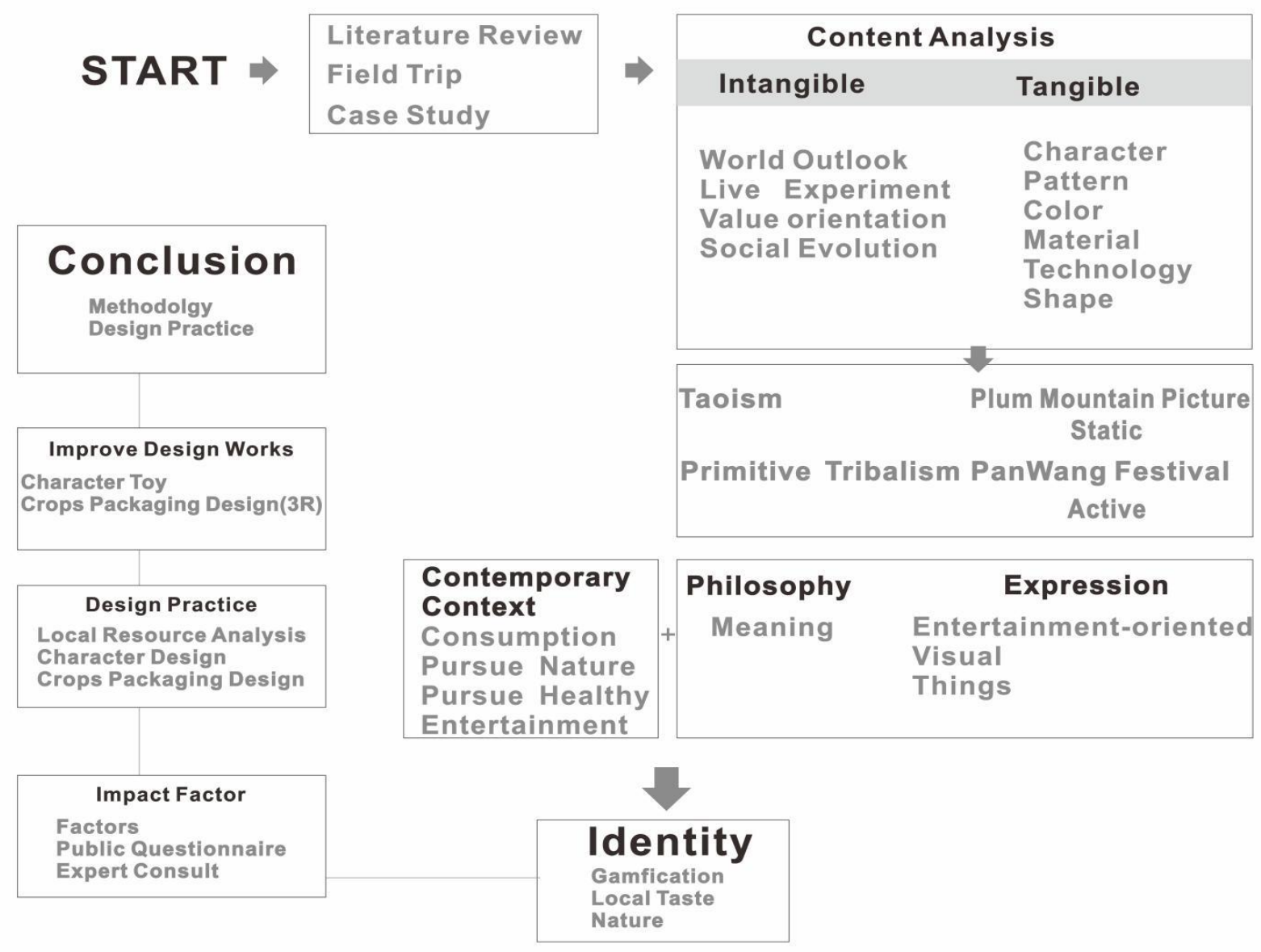

Fig. 1. Research framework.

\section{DATA COLLECT AND ANALYSIS}

\subsection{Data Collection}

Collect topic-related materials through expert interviews, local chronicles reading, museum visits, festival experience, focusing on the authenticity and typicality. The key point of this session is to organize effective interviews with old artists and inheritors who play a key role in traditional festivals, to learn more about the content arrangements of festivals and their reasons, and to learn about Philosophical significance about hanging statues, dances and props, costume patterns, songs. And then save and classify the videos, pictures, notes, physical samples and other materials.

The collection of data is divided into three steps: the first step is to interview Jiang Lifa, the inheritor of the intangible cultural heritage "Yao Blowing and Tart Drum Dance" in Guangxi, and the intangible cultural heritage of Guilin " Meishan Picture" Yang Shouming, the inheritor of "Traditional Painting Skills".

The second step is to visit the Yao Museum in Gongcheng City. The museum displays Yao ethnic costumes, ethnic architecture, festival scene simulation, etc., and conducts research on clothing modeling, pattern styles, materials, and fabric skills in the context of Yao ethnic festival culture, the museum display have the characteristics of artistic geography.

The third step is to read local Chronicles, monographs, picture albums and other books and watch video materials of festivals. This part focuses on collecting the recordings about myths and legends, and video materials. It uses databases such as National library, university libraries to search earlier published literature materials and works of authoritative experts, and draws descriptive relation maps of nouns and adjectives in description images and stories. In this paper, books such as History of the Yao Nationality, Selected Folk Stories of the Yao Nationality, Notes to Meishan Picture, and Paintings of Yao Statue in the Qing Dynasty were read to build a descriptive relationship map of the Pan Wang Festival of the Yao Nationality.

\subsection{Analysis of festival contents}

This part uses the content analysis method to analyze the "sacredness" construction process of the Yao ethnic Panwang Festival. From the human-centered perspective, analyze the eight relationships between human with God, history, language, human-self, time, geography, create things and matter(fig.2), and then, summarize the festival cultural core value and elements. 


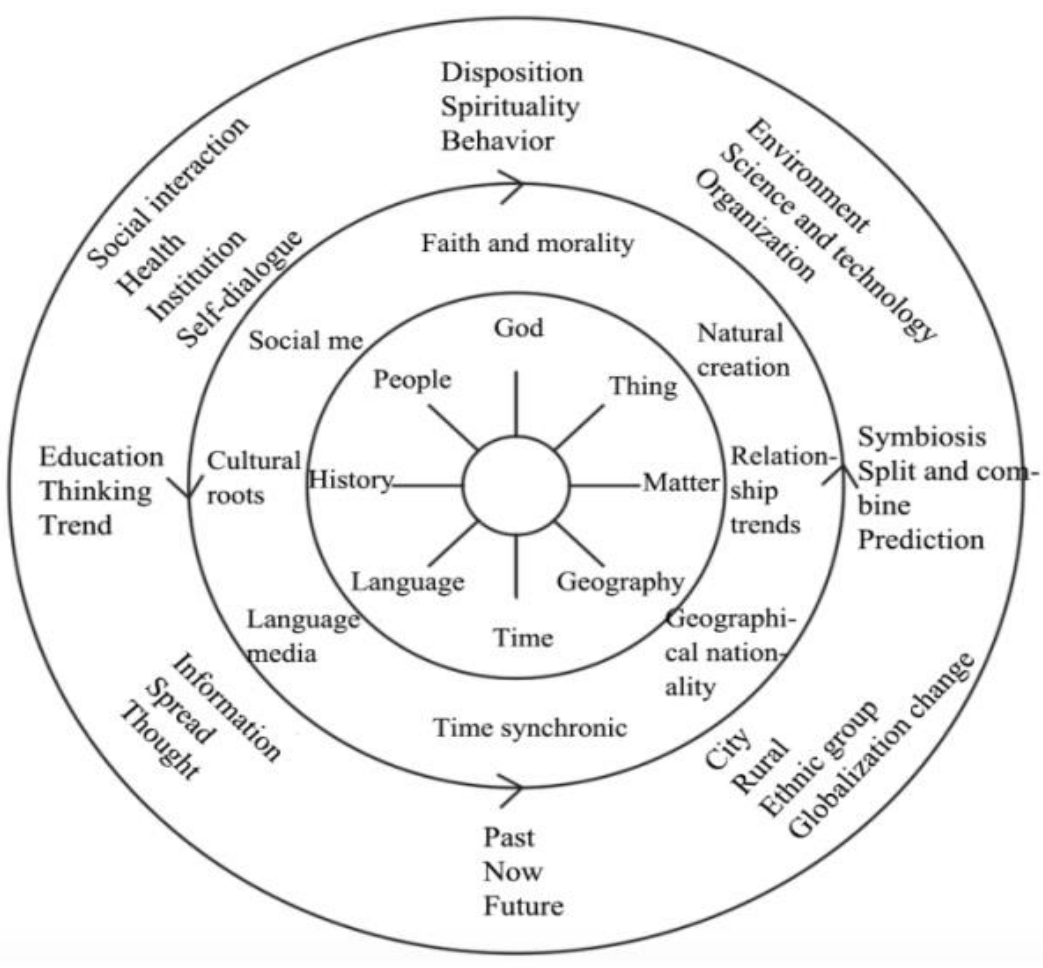

Fig. 2. Content analyse framework

The Yao nationality's Panwang Festival mainly consists of four parts: visual pictures space, vocal music and dance, Panwang song, and sacrificial activities. The visual image space as visual center by hanging Panwang statue and Taoist statues, red flags which drawn Yao nationality totems were arranged around the space, villagers wear costumes with ethnic characteristics. Sacrificial cases and offerings are set up in front of the Panwang statue. The theme, organization, and colors of the Yao costume patterns have special meanings, the patterns include dragon-dog pattern, sun flower, Panwang seal pattern, tree, human pattern, etc. Among them, dragon-dog is the ancestor of Yao nationality (Lu.W.X 1987). Sun flower, tree pattern, human pattern and other content reflect the Yao people's understanding of the external world, elements were arranged into the picture with balanced space, the space of each element look like equal, and the composition is harmonious and full. It embodies the world view of harmony and unity between man and nature respected by the Yao people. Its thinking can be traced back to the Taoist theory of "the harmony between man and nature". The vocal dance and Panwang song are carried out with different artistic expression simultaneously. The main content is to thank the Panwang for protect and pray for good luck. It advocates Yao ethnic group to unite and cooperate, be honest and trustworthy. Sacrificial activities mainly focus on offering cow , hunting, and agricultural products to show the characteristics of Yao nationality's production and lifestyle. Offerings are important production tools and crops, which are displayed with simple form (Tab.1).

Table 1. Analyse of panwang festival contents

\begin{tabular}{|l|l|l|l|}
\hline index & Main indicator & Secondary indicators & Note \\
\hline 01 & Man-Man & Clan, intermarriage & folk songs, local dance, \\
\hline 02 & Man-God & Ancestor worship & $\begin{array}{l}\text { Panwang portrait, Four Saints, dragon- } \\
\text { dog, Taoist statues, }\end{array}$ \\
\hline 03 & Man-Thing & Creation technology & Drum, building, cloth, food, \\
\hline 04 & Man-Matter & Live experience & Life-style \\
\hline 05 & Man-Geography & Geographical features & $\begin{array}{l}\text { Mountains, weather, birds, animals, } \\
\text { crops, leaf, etc. }\end{array}$ \\
\hline 06 & Man-Time & natural law & Twenty-four solar terms \\
\hline 07 & Man-Language & Panwang song, local-dialect & Antiphonal singing \\
\hline 08 & Man-History & Myth story & Gratitude, imagination \\
\hline
\end{tabular}




\section{ABM Method: The Application of Traditional Festival Elements in Interactive Packaging Design}

Publish questionnaires (more than or equal to 200 valid questionnaires) to obtain the following information:

Tourists have a deep memory of those objects in the festival culture?

Which part of the festival culture do tourists think is the most important?

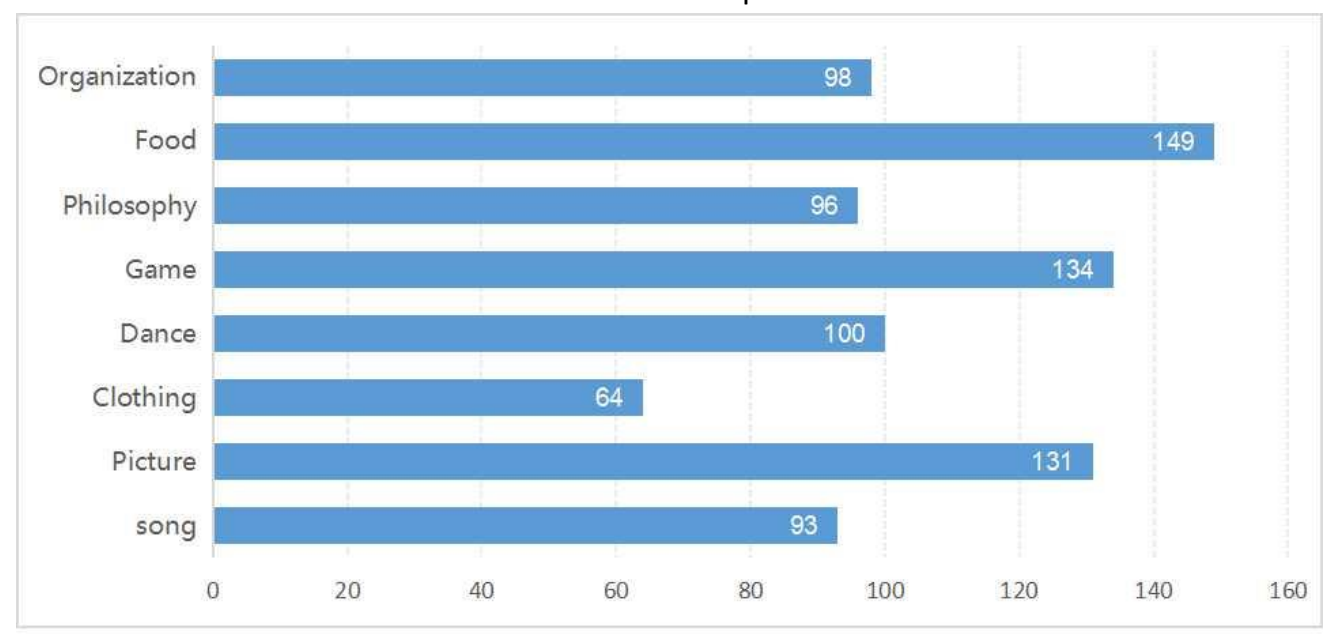

Fig.3. Demographic profiles about tourists deep memory objects ( $N=213$ male:91 female:112)

Through data analysis(fig.3), tourists have a high degree of memory for food, visual images and entertainment, Local food, visual images, participatory activities in Panwang Festival impress tourists, Base on this study will use hanging images and drums as the main carriers to convey the cultural spirit.

\section{BUILD CONNECTIONS BETWEEN TRADITIONAL FESTIVAL AND MODERN LIFE.}

\subsection{Agricultural civilization turns to consumer society}

Traditional festivals are the product of agricultural civilization, and their main social functions are to establish social organizations and shape collective character. Elements such as hanging images, food, and clothing in festivals have serious symbolic meanings. However, the postmodern society pays attention to entertainment, secularization and popularization, which eliminates the serious meaning contained in the images, the entertainment, participation and experience of festival culture have become important factors to attract tourists.

\subsection{Principles of building relationships between ancient and modern}

Globalization has accelerated the convergence of lifestyles, The festival culture which have local characteristic is an important resource to meet the requirements of mass tourism in postmodern society. People's life can be roughly divided into five aspects: food, clothing, housing, transportation and entertainment. Integrate festival elements such as ancient portraits and musical instruments into the modern consumption system. This study Follow the principles:

Concept level: Inheritance and Innovation of Excellent Cultural Spirit. For example, the continuation and regeneration of traditional cultural spirit in the modern context. respect for nature advocated by modern society, sustainable design, community with a shared future for mankind, etc.

Behavioral level: participatory, entertaining, enlightening cognition. The tourists' participation in festivals, they can gain a pleasant cultural experience and gain philosophical inspiration.

Material level: A Modern Expression of Traditional Elements. Using modern materials and production technology, the traditional elements are redesigned and applied to the fields of packaging, toys, clothing, interior decoration and so on.

The representative elements of the Yao nationality's Panwang festival was established through the "Analysis Table of Packaging Design"(tab.2). The content of this analysis table is mainly composed of eight types, including modeling, information transmission, production technology inheritance, materials, function expansibility, transportation, use process, and cultural regeneration. The stable can be as brainstorm tool and test tool on the stage of beginning or the evaluation.

Table 2. Packaging design elements

\begin{tabular}{|l|l|l|l|}
\hline index & Main indicator & Secondary indicators & Note \\
\hline 01 & Shape and Sound & Pattern. Colour. Building. Clothing. Food. instrument & drum \\
\hline 02 & information & Function, Fair story, Folk song & Health care, \\
\hline
\end{tabular}


ABM Method: The Application of Traditional Festival Elements in Interactive Packaging Design

\begin{tabular}{|l|l|l|l|}
\hline 03 & technology & $\begin{array}{l}\text { Weave. Sculpture. Embroidery. Ceramic. } \\
\text { Farm-tool. Building. painting }\end{array}$ & Rattan, dyeing \\
\hline 04 & Material & Regional, Reproducible, Process & Bamboo, Crop plant \\
\hline 05 & Function extension & Reuse, Recycle, Playability & Toy, Lighter, Etc. \\
\hline 06 & Transport protection & Normal, Special, Fragile & \\
\hline 07 & Using process & Easy, Simple, Interesting, Humanize. & philosophy \\
\hline 08 & Re-thinking & Inspire, Insight & \\
\hline
\end{tabular}

\section{MEDIA: INTERACTIVE PACKAGING DESIGN}

\subsection{Packing structure}

The packaging structure is the main part of the packaging design, and the packaging structure determines how the information is presented. After product packaging completes packaging function such as protecting goods and conveying brand information, whether its functions have the possibility to expand is an important factor to increase user viscosity. The packaging structure part focuses on consumer behavior guidance and user experience psychological process, according to product attributes to build flow-type space, such as centered, symmetrical, and sequential to create a dynamic spatial organization structure for effective transmit information through gradual visual display. Consumers get experience and information by actions such as dismantling, tearing, and pulling (He,J 2019). For example, the Yao oil tea packaging uses a long drum (representative instrument in Yao festivals) as the container, it is composed of five parts: two cups, two lids, and a connecting part, it can be separated into two independent containers, or can be combined into one as a drum which can be play. The box cover uses two layers of illustrations for dynamic display(fig.4).
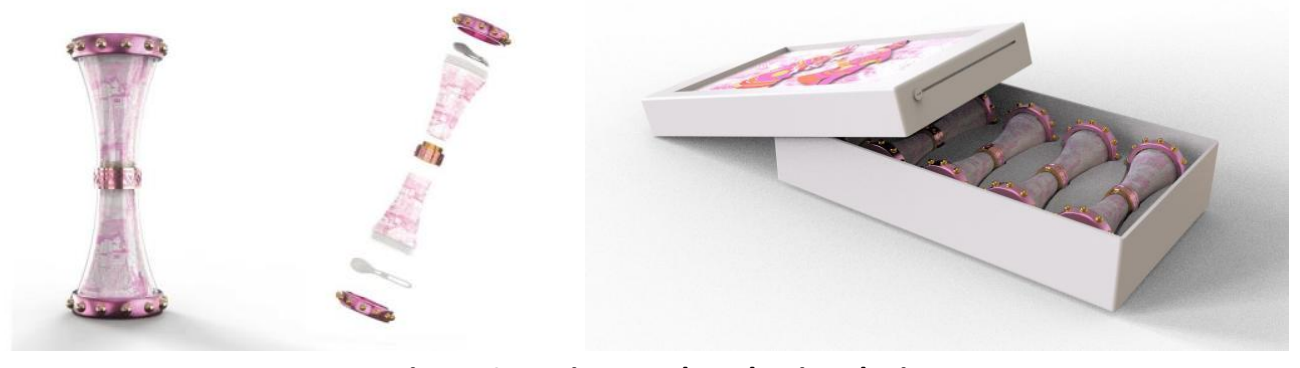

Fig. 4. Container and packaging design

The visual elements in festival activities are also one of the objects that tourists pay more attention to, such as character images, totem symbols, clothing patterns, etc. There are rich iconographic meanings behind the images. For example, the statues of Panwang and the four holy statues hanging in the Panwang Festival of the Yao nationality. In the context of consumption in post-modern society, the power of the image itself has disappeared, and it has turned to cultural experience. For example, the two-dimensional characters are cartoonized, and on the basis of retaining the packaging function, they have toys, teaching tools, etc., which are used as a carrier for children to exercise their hands-on ability, or for primary school students to understand local culture(fig.5).

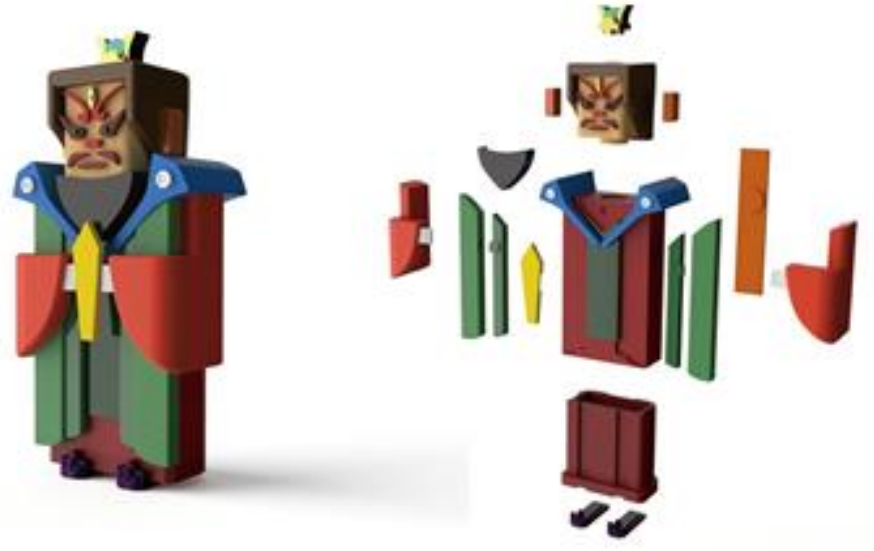

Fig. 5. Character as package, toy, or teaching tool 


\section{ABM Method: The Application of Traditional Festival Elements in Interactive Packaging Design}

\subsection{Packaging visual information}

In terms of packaging vision, the dynamic presentation of packaging information is closely related to the packaging structure. The packaging structure and visual information jointly build a consumer experience situation, actively attract consumers to interact with packaging, and subtly inspire consumers to think about the cultural spirit conveyed by packaging. For example, the labels of Yao tea bags are made into separate three-dimensional shapes, each label can be folded into different shapes, and finally combined into a large leaf, which contains real social landscapes such as cities, roads, and villages. The structure maps the living space of the real world and stimulates the philosophical thinking of consumers.

The mythological story text is the script of festival activities, and its content reflects the spiritual needs of the real society. The characters and their special functions in mythological stories have a deterrent power to shock the soul, and their essence is the interaction between man and God. For example, the "Panwang" of the Yao nationality, although it is a dog in a dragon robe, has a brave and witty humanoid character. Hunting and other activities during the Panwang Festival have cultivated a brave and industrious national character. Characters created based on text content help to visualize the text, such as Li Tianshi in charge of justice, generals on behalf of bravery, and water gods in charge of agricultural water resources. In addition, transforming the two-dimensional shapes of characters into three-dimensional shapes, such as packaging containers, toys, decorations, etc., in the context of digital media, can broaden the concept of interactive packaging, organically combine physical packaging with digital experience, and express facial expressions. The form of symbols and micro-videos convey festival culture and product characteristics (Funny Packaging Design 2019). For example, a general would design an emoticon package to convey the cultural spirit of the Yao people in the form of social language (Figure 6).
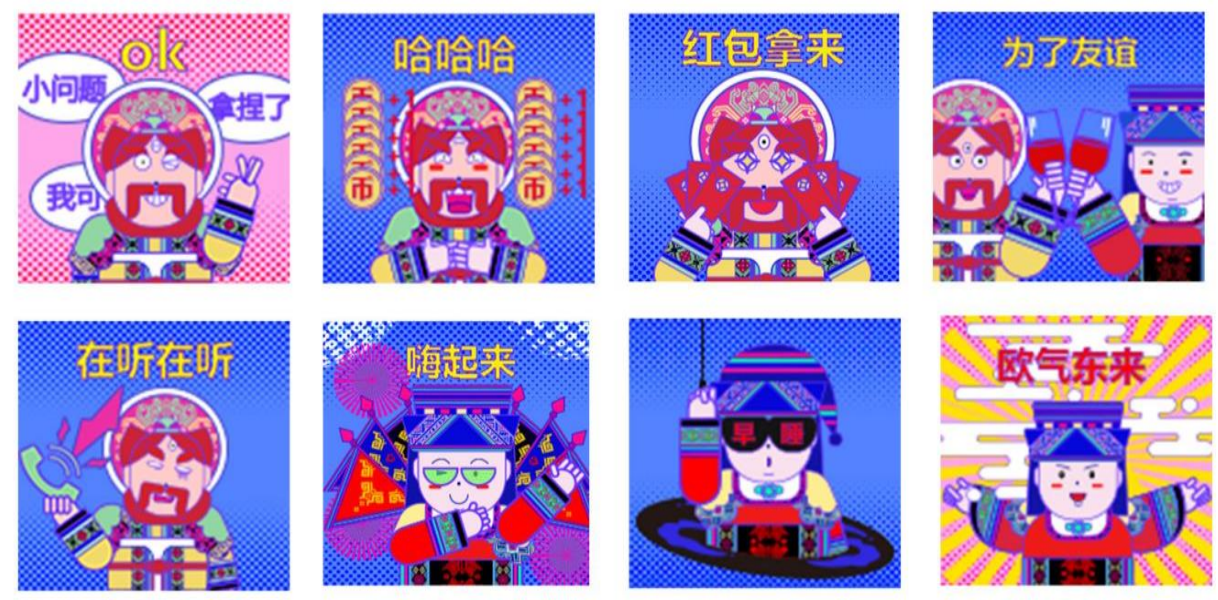

Fig. 6. Character design, emoji and models.

\subsection{Function extension}

The interactive packaging function presents diversification and openness. Packaging is defined as toys, teaching aids, handicrafts, etc. The function of interactive packaging is redefined according to customer needs, and is no longer just a box to protect goods. Interactive packaging helps to prolong the service life of packaging, improve the timeliness of information dissemination, promote the recyclability of packaging, and reduce the pollution of waste packaging to the environment. For example, transforming Panwang Festival food gift boxes into lamps to provide lighting or improve children's hands-on ability (fig.7).
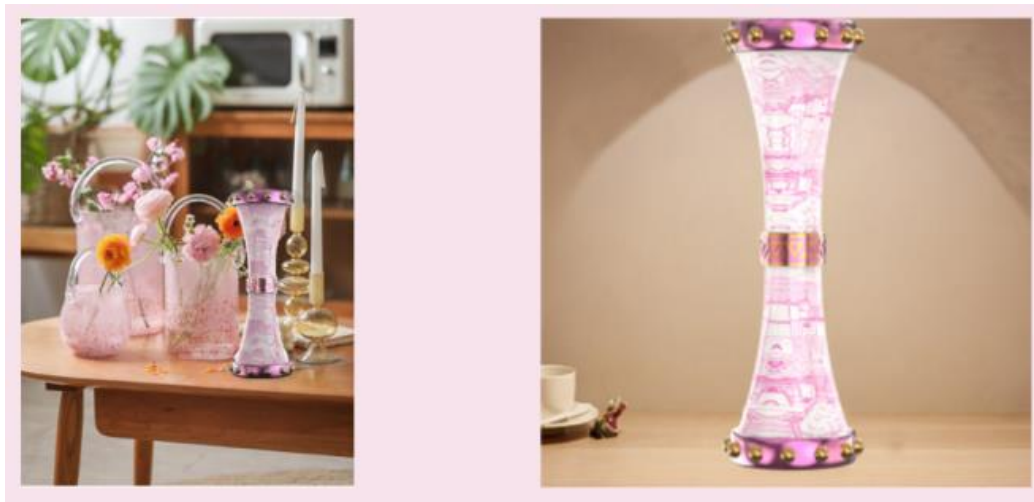

Fig. 7. Package transfer to lighter.

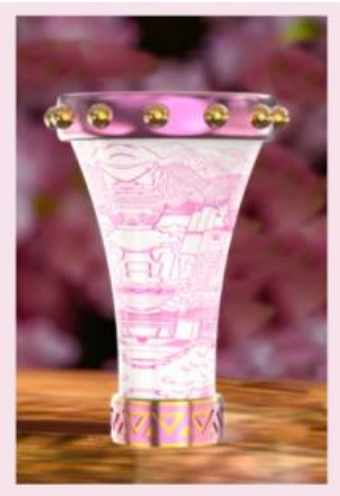




\section{ABM Method: The Application of Traditional Festival Elements in Interactive Packaging Design \\ CONCLUSION}

The focus of this research is to apply traditional cultural elements to modern product design through the analysis of the content of traditional festival culture. This paper takes the application of Yao ethnic Panwang Festival elements to interactive packaging design as an example, which helps to display ethnic minorities dynamically and interestingly. Festival culture and cultural spirit to establish a good relationship between consumers and packaging. The significance of this work is that interactive packaging will extend the packaging life cycle, increase functional scalability, reduce packaging waste, and reduce environmental pollution. From the perspective of cultural connotation, interactive packaging design can be an important part of enhancing the image of the festival.

This research is supported by the "Review the Past to Understand the Present-Research on the Packaging Design of Local Products Based on 'Traditional Festival Culture'"(Guangxi Education Department No. 2020KY06050).

\section{REFERENCES}

1) Liu, B. (2017). Folk festivals and local identity: a comparative study of multiple cases from Guangzhou. Beijing: The Commercial Press. Page 013.

2) Lu, W. X. (1987). History of Yao Ethnic Story. Nanning: guangxi people publishing company.

3) He, J. (2019). Modern Packaging Design. Beijing: Tsinghua University Press.

4) Take Me Away: Funny Packaging Design. (2019). Designer Books.

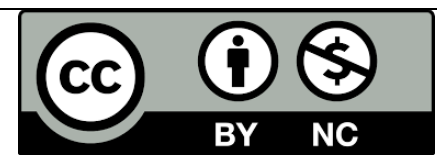

There is an Open Access article, distributed under the term of the Creative Commons Attribution - Non Commercial 4.0 International (CC BY-NC 4.0) (https://creativecommons.org/licenses/by-nc/4.0/), which permits remixing, adapting and building upon the work for non-commercial use, provided the original work is properly cited. 